Estudios Constitucionales, Año 10, No 2, 2012, pp. 429 - 454.

ISSN 0718-0195

Centro de Estudios Constitucionales de Chile Universidad de Talca

"La jurisdicción constitucional entre judicialización y activismo judicial: ¿existe realmente 'un activismo' o 'el' activismo?"

Mônia Clarissa Hennig Leal

\title{
LA JURISDICCIÓN CONSTITUCIONAL ENTRE JUDICIALIZACIÓN Y ACTIVISMO JUDICIAL: ¿EXISTE REALMENTE "UN ACTIVISMO" O "EL" ACTIVISMO?1
}

\author{
JUDICIAL REVIEW BETWEEN JUDICIALIZATION AND JUDICIAL ACTIVISMO: \\ IS THERE REALY “AN” OR “THE” ACTIVISM?
}

Mônia Clarissa Hennig Leal ${ }^{2}$

Profesora de Derecho Constitucional Universidad de Santa Cruz do Sul - UNISC (Brasil)

moniah@unisc.br

RESUMEN: La jurisdicción constitucional ha ganado relieve en el contexto del Estado Constitucional, en cuanto garantizadora de la Constitución y de sus derechos fundamentales, siendo frecuentes las referencias a fenómenos como "judicialización" y "activismo judicial". Lo que se busca es analizar estos conceptos y algunas teorías respecto a la legitimidad de la jurisdicción, demostrando como ellos no poseen contenido univoco, lo que dificulta el debate sobre la materia.

ABSTRACT: Judicial review became very important in the context of Constitutionalism, while instance of protection and guarantee of the Constitution and its fundamental rights. This conduces to concepts like "judicialism" and "judicial activism", that intend to be analyzed -as well as some theories about the legitimacy of judicial review - in the way to show how empty they can be, what sometimes makes an adequate debate about this question very difficult.

Palabras Clave: Jurisdicción constitucional. Judicialización. Activismo judicial. Democracia. Legitimidad.

KEY WORDS: Judicial review. Judicialization. Judicial activism. Democracy. Legitimacy.

\footnotetext{
${ }^{1}$ Este artículo es resultante del proyecto de investigación "O amicus curiae como instrumento de realização de uma Jurisdição Constitucional aberta: análise comparativa entre os sistemas brasileiro, alemão e norte-americano e de sua efetividade nas decisões do Supremo Tribunal Federal", financiado por el Conselho Nacional de Desenvolvimento Científico e Tecnológico-CNPq y por la Fundação de Amparo à Pesquisa do Rio Grande do Sul-FAPERGS. El presente texto integra, también, los estudios realizados junto al grupo de investigación "Jurisdição Constitucional aberta", del Programa de Postgrado en Derecho - Magíster y Doctorado de la Universidade de Santa Cruz do Sul - UNISC, vinculado al CNPq, de lo cual la autora es coordinadora, y del proyecto de investigación "Controle jurisdicional de Políticas Públicas". Artículo recibido el 30 de enero de 2012 y aprobado el 10 de octubre de 2012.

2 Doctora en Derecho por la Universidade do Vale do Rio dos Sinos - Unisinos, con investigación de tesis realizada junto a la Ruprecht-Karls Universität Heidelberg, en Alemania. Profesora del Programa de Postgrado en Derecho - Magíster y Doctorado de la Universidade de Santa Cruz do Sul - UNISC, donde enseña las disciplinas de Jurisdicción Constitucional y Control Jurisdiccional de Políticas Públicas, respectivamente. Coordinadora del Grupo de Investigación "Jurisdição Constitucional aberta", vinculado al CNPq. Becaria de productividad en investigación del CNPq.
} 


\section{INTRODUCCIÓN}

La jurisdicción constitucional ha ganado gran relieve en el contexto del Estado Constitucional, en cuanto garantizadora de la Constitución y de los derechos fundamentales. Su prominencia es expresiva, a su vez, de la propia centralidad y supremacía que caracterizan su objeto de control. En este proceso, con todo, al ejercer sus competencias, los tribunales constitucionales acaban por ser criticados y cuestionados acerca de los límites y de la legitimidad de su actuación. Palabras como "judicialización” y "activismo judicial” aparecen, entonces, de forma recurrente. Estos conceptos son, no obstante, muchas veces empleados indistintamente, con carácter retórico, no siendo analizados y utilizados de manera correcta, lo que conduce a confusiones terminológicas que en nada ayudan para que se tenga un debate adecuado sobre el tema.

En este contexto, el presente artículo intenta enfrentar algunos aspectos centrales a esta discusión. Su objeto se refiere, por lo tanto, más a una contribución en el sentido de calificación del debate que a una búsqueda de una respuesta directa del problema. Por tanto, se delinea, en un primer momento, una rápida evolución histórica acerca de la jurisdicción constitucional y de los aspectos que conducen a las nociones de "judicialización” y de "activismo judicial", abordadas en el segundo punto, donde se busca contrastar y distinguir, de forma sistemática, los conceptos. Por fin, en el último tópico, se intenta analizar algunas de las teorías respecto a la legitimidad de la jurisdicción constitucional, evidenciándose las imprecisiones y dificultades que se pueden verificar con relación a algunos de sus elementos fundamentales. Lo que se pretende, por lo tanto, es contribuir, a partir de las reflexiones trazadas, para una mejor comprensión de estos aspectos, para que se pueda calificar y profundizar el enfrentamiento de la materia, así como la propia actuación de la jurisdicción constitucional y su contribución para la democracia.

\section{LA JURISDICCIÓN CONSTITUCIONAL EN EL ORDEN DEMOCRÁTICO:}

los Tribunales Constitucionales como "señores de la Constitución”

El activismo judicial, asociado a una postura activa e intervencionista de los Tribunales Constitucionales en el sentido de realización de la Constitución y de concretización de los derechos fundamentales, viene siendo uno de los aspectos más controvertidos y discutidos de la Teoría Constitucional contemporánea, especialmente en lo que dice respecto a su legitimidad democrática, delante de 
una -supuesta- violación del principio de separación de los poderes, pues, al intentar llevar a cabo sus tareas constitucionales, el Poder Judicial acaba, muchas veces, siendo acusado de invadir competencias reservadas a los poderes públicos representativos, actuando, así, de manera positiva, y no meramente negativa, como originariamente fue pensada su función.

En este sentido, es posible percibir que la actual jurisdicción constitucional en nada se parece con el control de constitucionalidad inaugurado en el célebre caso Marbury v. Madison ${ }^{3}$ (1803), en Estados Unidos, que inauguró, casi "accidentalmente" ${ }^{4}$, el fenómeno. John Marshall, participando del juzgamiento en cuanto juez, consideró que la ley que servía de fundamento a la acción impetrada -llamada writ of mandamus- era inconstitucional, una vez que confería a la Suprema Corte poderes que originariamente no le habían sido atribuidos, no pudiendo, por lo tanto, su competencia ser ampliada sino que por la propia Constitución. Ha sostenido, entonces, la tesis de que la Constitución es la base de todos los derechos y la ley suprema del ordenamiento, de modo que su contenido es inmodificable por las vías ordinarias, o sea, las demás leyes deben estar de acuerdo con sus principios, justificándose, así, el control de los actos legislativos contrarios a ella -porque lo contrario implicaría la aceptación de la idea de que un acto legislativo cualquiera puede modificarla. ${ }^{5}$

La idea de control allí desarrollado, con todo, se parece muy poco a la realidad de la jurisdicción constitucional actual. ${ }^{6}$

De la misma forma, tampoco el Tribunal Constitucional idealizado por Hans Kelsen (con ocasión de su célebre debate con Carl Schmitt, en medio a

\footnotetext{
${ }^{3}$ Consta en los asientos históricos que John Marshall, el "autor" de la teoría de la inconstitucionalidad, era amigo del entonces Presidente americano Adams, que, en el último día de su gobierno, había nombrado una serie de correligionarios suyos para ocupar cargos públicos; ni todos los beneficiados, sin embargo, recibieron sus actos de asunción al cargo, que fueron, en seguida, suspendidos por el nuevo Presidente, Thomas Jefferson. Uno de los perjudicados, llamado Marbury, que había sido indicado para ser juez de paz y no fue oficializado a tiempo, ingresó, entonces, con una acción conocida como writ of mandamus ante la Suprema Corte para obligar al nuevo Secretario de Estado, Madison, a hacerlo. Surge, así, el famoso caso Marbury v. Madison.

${ }^{4}$ Se hace oportuno resaltar que la figura del control de constitucionalidad no aparece expresamente prevista en el texto de la Constitución americana de 1787; trátase, antes, de una construcción hecha a partir de ella. En este sentido, ver la obra de CoElho, (1992), pp. 72 et seq., que trae una amplia y rica gama de informaciones sobre el tema.

${ }^{5}$ Conforme Silva, (1992), p. 30.

${ }^{6}$ Häberle, (1982).
} 
los intentos de estabilización de la República de Weimar ${ }^{7}$, en Alemania, acerca de a quién corresponde mejor la tarea de custodia de la Constitución) podría imaginar en lo que él se transformaría en el actual contexto democrático.

Tal sistema, al adoptar una lógica concentrada de control, difiere, a su vez, del judicial review americano - de carácter difuso - toda vez que confía a un único y sólo órgano, el Tribunal Constitucional, la tarea de preservar la Constitución. ${ }^{8}$ Kelsen ha concebido el control de constitucionalidad como una función no propiamente jurisdiccional, sino que de "legislación en sentido negativo", al cual cabe analizar solamente el problema (puramente abstracto) de compatibilidad lógica entre la ley y la Constitución. Trátase, por consiguiente, de una actividad que se aproxima a la del legislador, ya que posee una dimensión general y abstracta, y no una decisión singular y concreta, típica de la actividad jurisdiccional. ${ }^{10}$

Además, se ha buscado construir, a partir del rescate de la noción de volonté générale, una legitimidad y legitimación indirectas ${ }^{11}$, adoptándose, así, una comprensión que destaca la supremacía de la Constitución, pero sin comprometer la esencia del mito de la soberanía legislativa, tan cara al derecho continental europeo. ${ }^{12}$ De este modo, el Tribunal Constitucional, de concurrente del Parlamento, se ha convertido en su complemento lógico, realizando no una apreciación del mérito o contenido de la ley, sino tan sólo su validez (de ahí que se hable de él como un "legislador negativo"). ${ }^{13}$

Hubo, sin embargo, especialmente a partir de la segunda postguerra, un alejamiento, de parte de los Tribunales Constitucionales europeos (particularmente

\footnotetext{
7 Sobre la estructura de la jurisdicción constitucional en la República de Weimar, ver el rescate histórico hecho por RobBers, (1990), p. 262.

${ }^{8}$ A título ilustrativo, confirmando lo que fue dicho arriba, André Ramos Tavares, en su libro sobre la figura de la jurisdicción constitucional, trae un interesante levantamiento acerca de las Constituciones alrededor del mundo que acabaron por incorporar el sistema "kelseniano" de control de constitucionalidad de las leyes. TAVARES, (2005), pp. 81 et seq.

${ }^{9}$ Kelsen, (1929a), p. 81.

${ }^{10}$ Kelsen, (1929b), p. 57.

${ }^{11}$ Regístrese que, en la mayoría de los países, la indicación de los integrantes del Tribunal es hecha por el Parlamento, constituyéndose de un mandato fijo. Ver HaAs, (2004), p. 104.

${ }^{12}$ Tal aspecto gana destaque, sobre todo, en la percepción de Enterría, al tenerse presente el riesgo que representaba la adopción de un sistema de control de constitucionalidad de las leyes, especialmente en Alemania, donde las posiciones románticas de la Escuela Libre del Derecho alimentaban una revuelta de los jueces contra la ley. Cf. EnTERría, (1985), p. 58.

${ }^{13}$ Haltern, (1998), p. 210.
} 
en países como Alemania, Italia, España y Portugal), del modelo de control propuesto por Kelsen ${ }^{14}$, que pasó a incorporar y adquirir nuevas dimensiones.

La actual actividad jurisdiccional de esos Tribunales sobrepasa, en cierta medida, la función meramente "negativa" de control, adquiriendo una dimensión constructiva y creativa, asentada en la necesidad de concreción de los principios $\mathrm{y}$ de los derechos fundamentales inscritos en los textos de las constituciones, donde figuras como las sentencias interpretativas y las sentencias manipulativas $^{15}$ se tornan cada vez más frecuentes, así como los recursos a instrumentos hermenéuticos que viabilizan su realización, aun cuando eso implique una transposición de las funciones que originariamente le fueron reservadas.

Ante tal cuadro, no tardaron las críticas a lo que se ha dado llamar "activismo judicial", estando la mayoría de ellas basada en el argumento del paternalismo ${ }^{16}$ representado por la jurisprudencia de valores incorporada por estos Tribunales, que pasan a ser, en la designación de Böckenförde ${ }^{17}$, los "señores de la Constitución" (Herren der Verfassung).

El fenómeno del activismo judicial no puede, no obstante, ser confundido con el fenómeno de la judicialización, siendo que ambos, muchas veces, son tomados como sinónimos; a pesar de que sean dos caras de la misma moneda, ambos poseen fundamentos distintos. Esta "confusión" o imprecisión metodológica en nada contribuye, sin embargo, para una reflexión adecuada acerca del tema y de sus implicaciones en el ámbito de la legitimidad de la jurisdicción constitucional. Así, se va a intentar, en el tópico siguiente, analizar estos

\footnotetext{
${ }^{14}$ Sobre el proceso de alejamiento del modelo original kelseniano que marca la actuación de los Tribunales Constitucionales en Europa, ver el texto de SánCHEZ, (1998), pp. 67 et seq.

${ }^{15}$ Las sentencias interpretativas pueden ser tenidas como aquellas en que el Tribunal, para dar cuenta de su tarea de custodia y de realización de la Constitución, se vale de recursos hermenéuticos e interpretativos - tales como las figuras de la interpretación conforme con la Constitución y de la nulidad parcial sin reducción de texto- para asegurar la constitucionalidad de los dispositivos legales cuestionados. Ya en el caso de las llamadas sentencias manipulativas (aditivas, reductivas o sustitutivas), el Tribunal, con la misma finalidad de asegurar la conformidad de determinada norma con la Constitución, prefiere manipularla textualmente, esto es, alterar su texto original (acrecentando, retirando o sustituyendo, respectivamente, conforme el caso), evitando, así, la declaración de inconstitucionalidad. Así, como en el último caso, el Judicial acaba por "crear" normas, más que solamente interpretarlas, sustituyendo, por veces, la actuación del legislador. Sobre las sentencias interpretativas y manipulativas, ver nuestro texto Leal, (2006), pp. 1563-1586. También (Abellán, (2003), Elia, (1987). En Brasil, la temática es enfrentada por MENDES, (1998), STRECK, (2001).

${ }^{16}$ En este sentido, se destaca, por ejemplo, la obra de Maus, (2000).

${ }^{17}$ La expresión aparece en diferentes momentos de la obra del autor, como, por ejemplo, en BÖCKENFÖRDE, (1999), p. 132.
} 
dos conceptos en sus causas y particularidades, a fin de que puedan ser mejor comprendidos y, consecuentemente, sea posible una apreciación crítica más consistente en relación a ellos.

\section{JUDICIALIZACIÓN Y ACTIVISMO JUDICIAL: DOS CARAS DE LA MISMA MONEDA, PERO NO NECESARIAMENTE LA MISMA MONEDA}

Cuando se discuten las funciones y la actuación de la jurisdicción constitucional en el actual contexto democrático, son recurrentes las referencias a fenómenos como "judicialización" y "activismo judicial". Pese a que muchas veces esos términos son empleados de forma vinculada o como sinónimos, ambos no pueden ser confundidos, pues poseen características y causas distintas.

La judicialización es resultado, de una manera general, de un proceso histórico típico del constitucionalismo democrático que tiene por base múltiples factores, tales como la centralidad de la Constitución y su fuerza normativa, asociadas a aspectos como el carácter principista, la supremacía y la dimensión objetiva de los derechos fundamentales, que, tenidos como vinculantes, resultan en conceptos como el de la Austrahlungswirkung ${ }^{18}$ y de la Drittwirkung ${ }^{19}$, que, sumados, conducen a una ampliación y a una transformación de la naturaleza de la jurisdicción constitucional, como ya he referido en el tópico anterior. Su principal característica reside, por lo tanto, en un protagonismo del Poder Judicial, resultante de una confluencia de factores que llevan a una transferencia de decisiones estratégicas sobre temas fundamentales de la sociedad (históricamente reservadas para las instancias políticas y deliberativas) para este Poder, lo que hace que el derecho se convierta, cada vez más, en un derecho judicial, construido, en el caso concreto, por los magistrados. ${ }^{20}$ Sus principales aspectos, en nuestra comprensión, pueden ser visualizados en el cuadro esquemático abajo:

\footnotetext{
18 SChlink, (1989).

19 SCHWABE, (1971).

${ }^{20}$ La innovación no reside, aquí, tanto en la comprensión de la jurisprudencia como fuente del Derecho, sino que en su relevancia, pues ella pasa, en este proceso, de fuente complementaria a elemento central de conformación del orden jurídico, ya que la actuación del magistrado, en el fallo concreto, se presenta como determinante para la conformación del derecho, por medio de una actividad creativa, constructiva, de integración del texto normativo con la realidad. Es posible percibir, por lo tanto, una transformación en la comprensión de la actividad interpretativa (asociada al giro lingüístico y a la llamada "Nueva Hermenéutica"), bien como a una transformación del propio Derecho, que, al adquirir un carácter principista y valorativo, vinculado, especialmente, a los derechos fundamentales, demanda una actuación diferenciada del juzgador en su conformación y concretización. Es en esta perspectiva, por lo tanto, que se puede
} 


\begin{tabular}{|c|c|c|}
\hline Judicialización & \multicolumn{2}{|c|}{$\begin{array}{l}\text { a) de la política } \rightarrow \text { relación del Judicial con los demás poderes -posible } \\
\text { "intervención” en las competencias del Ejecutivo (ej.: control jurisdiccio- } \\
\text { nal de políticas públicas) y del Legislativo (ej.: definición de derechos, } \\
\text { creación de normas) } \\
\text { b) del derecho } \rightarrow \text { tendencia de un derecho cada vez más jurisprudencial } \\
\text { “judge made law”, en contrapunto al derecho legislado (ej.: especificación } \\
\text { del contenido y extensión del derecho en el fallo concreto) }\end{array}$} \\
\hline Caracteristicas & \multicolumn{2}{|c|}{$\begin{array}{l}\text { Transferencia de decisiones estratégicas para el Judicial, especialmente } \\
\text { para los tribunales constitucionales (decisiones sobre temas polémicos y } \\
\text { tendencialmente en principio más asociados a la deliberación política -ej.: } \\
\text { interrupción de la gestación, investigaciones científicas y manipulación } \\
\text { genética(s), etc.). }\end{array}$} \\
\hline \multirow[b]{2}{*}{$\begin{array}{l}\text { Causas de la } \\
\text { judicialización } \\
\text { del derecho }\end{array}$} & \multirow[b]{2}{*}{ a) Derechos Fundamentales } & $\begin{array}{l}\text { - supremacía } \rightarrow \text { derechos fundamentales } \\
\text { como elementos centrales del orden } \\
\text { jurídico (tribunales constitucionales } \\
\text { precisan decidir sobre cuestiones que } \\
\text { envuelven la incidencia de esos dere- } \\
\text { chos -ej.: incidencia en las relaciones } \\
\text { privadas, independientemente de re- } \\
\text { glamentación) }\end{array}$ \\
\hline & & $\begin{array}{c}\text { - } \text { apertura, carácter principista } \rightarrow \text { los } \\
\text { derechos fundamentales están conte- } \\
\text { nidos en los textos constitucionales de } \\
\text { forma principista, demandando, así, } \\
\text { una concreción y determinación de sus } \\
\text { contenidos en los fallos concretos, que } \\
\text { necesitan ser decididos por el Judicial } \\
\text { (ej.: extensión e incidencia del principio } \\
\text { de la igualdad -constitucionalidad de la } \\
\text { reserva de cuotas para estudiantes negros } \\
\text { en las universidades, abertura del merca- } \\
\text { do de trabajo para las mujeres, etc.) }\end{array}$ \\
\hline
\end{tabular}

hablar de una cierta aproximación entre los sistemas de la common law (jurisprudencial) y de la civil law (legalista), pues este último viene, progresivamente, reconociendo mayor espacio y relevancia a la actividad jurisdiccional, vinculada a la aplicación del derecho -aun que legislado- al fallo concreto. Sobre el giro lingüístico y sus reflejos en la interpretación, HeIDEGGER, 1986, GADAMER, (1972). Respecto de la "Nueva Hermenéutica" y de la jurisprudencialización del derecho, ver KoCH, (1986), IsENSEE, (1996); también Cittadino, (2002), pp. 17-42. 


\begin{tabular}{|c|c|}
\hline & $\begin{array}{l}\text { - conflictos entre derechos fundamenta- } \\
\text { les } \rightarrow \text { la ocurrencia de conflicto entre } \\
\text { derechos fundamentales presupone una } \\
\text { ponderación -en el fallo concreto- que } \\
\text { acaba teniendo que ser decidida por el } \\
\text { Judicial (ej.: límites de la libertad de } \\
\text { expresión X derecho a la intimidad y } \\
\text { a la privacidad con relación a materias } \\
\text { periodísticas; libertad religiosa X dere- } \\
\text { cho a la vida en los casos de transfusión } \\
\text { de sangre, etc.) }\end{array}$ \\
\hline & $\begin{array}{l}\text { - tutela y protección de situaciones no } \\
\text { reglamentadas por la legislación } \rightarrow \\
\text { la incidencia directa de los derechos } \\
\text { fundamentales hace que ellos operen y } \\
\text { sean aplicados también en situaciones } \\
\text { no reglamentadas por la legislación (ej.: } \\
\text { en nombre de la igualdad, se recurre a } \\
\text { los jueces para el reconocimiento de } \\
\text { uniones afectivas entre homosexuales; } \\
\text { en nombre de la libertad y de la auto- } \\
\text { nomía de la voluntad se recurre a ellos } \\
\text { para que autoricen la interrupción de } \\
\text { la gestación de fetos anencefálicos o la } \\
\text { desconexión de aparatos de pacientes } \\
\text { en estado vegetativo, en principio no } \\
\text { excluidas por la legislación penal de la } \\
\text { tipificación del homicidio) }\end{array}$ \\
\hline $\begin{array}{l}\text { b) ampliación y alcance de la } \\
\text { Constitución }\end{array}$ & $\begin{array}{l}\text { Constitución formal y escrita (analítica) } \\
\rightarrow \text { en nombre de la seguridad jurídica, se } \\
\text { inserta una gran cantidad de contenidos } \\
\text { en los textos constitucionales, que pasan } \\
\text { a tener status de norma constitucional y a } \\
\text { funcionar como parámetros para el con- } \\
\text { trol de constitucionalidad, que, con eso, } \\
\text { tiene sus espacios y materias de actuación } \\
\text { ampliados }\end{array}$ \\
\hline $\begin{array}{l}\text { c) constitucionalización del } \\
\text { Derecho }\end{array}$ & $\begin{array}{l}\text { eficacia de irradiación (Austrahlungswir- } \\
k u n g) \rightarrow \text { la jurisdicción constitucional } \\
\text { determina la interpretación del derecho } \\
\text { infraconstitucional de manera "conforme }\end{array}$ \\
\hline
\end{tabular}




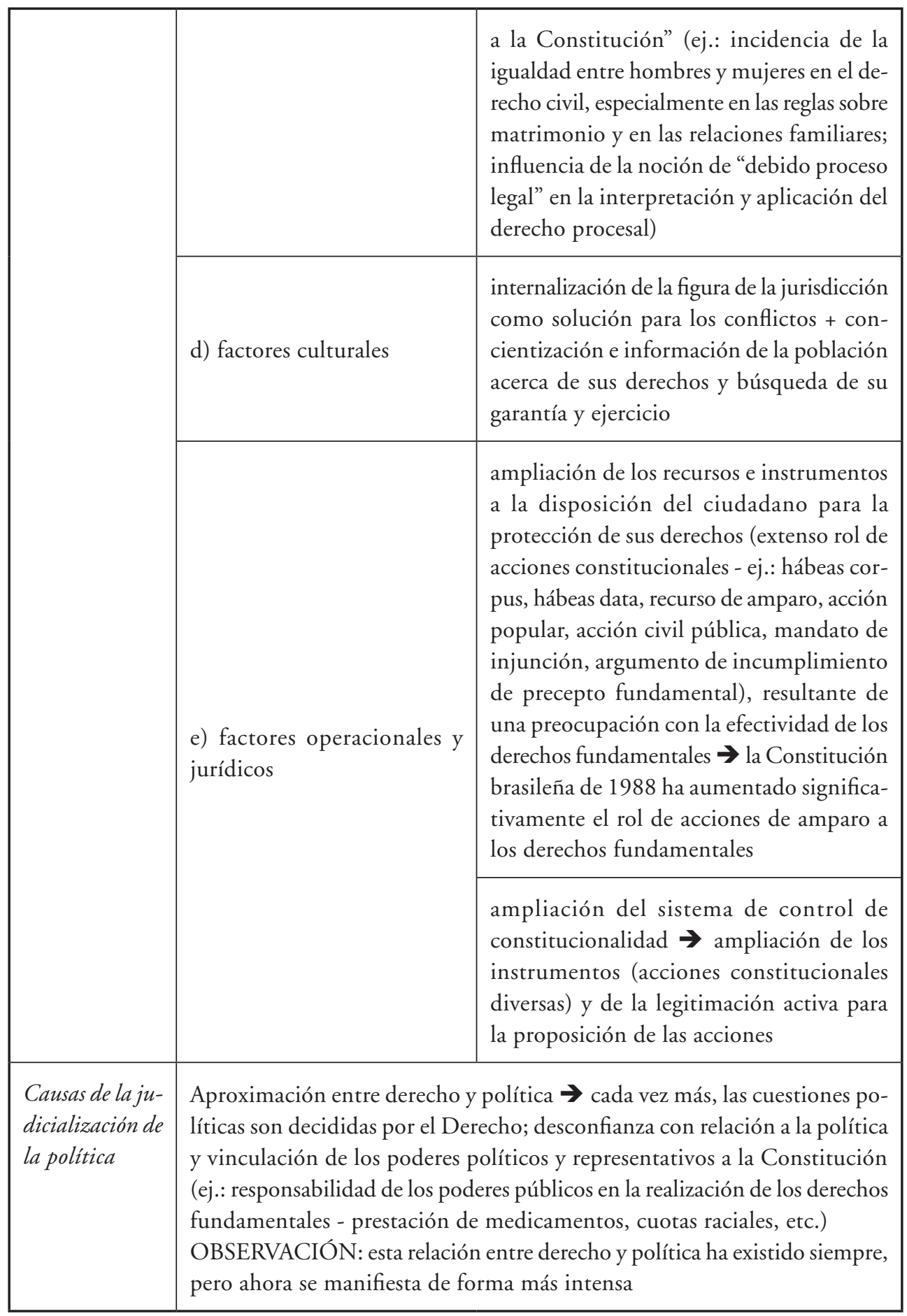


A pesar de ser la judicialización un fenómeno relativamente reciente, la aproximación y la relación entre derecho y política, con todo, no es nueva. En rica reflexión acerca del tema, el autor alemán Dieter Grimm ${ }^{21}$ sostiene que la tensión entre derecho y política siempre ha existido y ha cambiado en el tiempo, existiendo momentos en que la política ha subyugado el derecho y viceversa; en tal contexto, la relación entre ellos cambia y se alterna, pero no se extingue, no puede ser suprimida. Según el constitucionalista, la separación entre derecho y política es, no obstante, una separación de carácter meramente institucional (y no propiamente real), lo que no garantiza, entre tanto, que el procedimiento de aplicación judicial del derecho sea también internamente apolítico.

Dentro de este contexto, resalta el pensador que la figura de la jurisdicción constitucional se constituye en un caso especial, y aunque ella misma sea institucionalmente parte integrante del Poder Judicial, se encuentra mucho más próxima de la política que otros órganos; esto porque las normas constitucionales poseen un carácter de principio más fuerte, abriendo un mayor margen a la interpretación y exigiendo procesos de concreción más abiertos. Además, el objeto de reglamentación de la Constitución y, por lo tanto, el objeto de control del Tribunal Constitucional reside en la política, razón por la cual las fronteras entre derecho y política, en este caso, son más tenues.

El activismo judicial, a pesar de tener también como telón de fondo la relación entre derecho y política, posee fundamentos distintos, estando más relacionado a una perspectiva interna, vinculada a la actuación del Poder Judicial en el desempeño de sus competencias, más allá de los factores históricos mencionados que condujeron al fenómeno de la judicialización, siendo identificado, en la mayoría de las veces, con una postura proactiva del juzgador. ${ }^{22}$

Así, la actuación de los magistrados es frecuentemente cuestionada y criticada, bajo el argumento de que, a veces, en nombre de la realización de los derechos fundamentales ${ }^{23}$, ellos extrapolan los límites de competencia fijados

\footnotetext{
${ }^{21}$ Grimm, (2006), pp. 14-16 passim.

${ }^{22}$ Un intento en el sentido de diferenciar los fenómenos de la judicialización y del activismo judicial puede ser encontrada en BARROSO, (2009).

${ }^{23}$ Interesante manifestación en este sentido, explicitando la posición de que al Tribunal Constitucional cabe la salvaguardia de la Constitución y de los derechos fundamentales, aunque esto implique en cierto "activismo", puede ser encontrada en el discurso del Ministro Celso de Mello, del Supremo Tribunal Federal brasileño, por ocasión de la asunción del Ministro Gilmar Ferreira Mendes a la presidencia de la Corte, donde se lee que "nem se censure eventual ativismo judicial exercido por esta Suprema
} 
por la Constitución, invadiendo la esfera de los demás poderes y poniendo en riesgo el propio sistema democrático. ${ }^{24}$

El constitucionalista americano Mark Tushnet ${ }^{25}$ hace, con todo, una interesante reflexión acerca de las dificultades hermenéuticas y pragmáticas que la expresión "activismo judicial" trae consigo, especialmente delante de la inexistencia de criterios posibles o claros para establecerse cuando una decisión puede ser clasificada como "activista" (alias, el autor intenta demostrar, basado en una serie de ejemplos, que, para determinar lo que significa ser "activo" se hace necesario, antes, que se establezcan los estándares o criterios de cual sería el patrón "normal" de juzgamiento, aspecto que, igualmente, se presenta imposible, delante de la abertura interpretativa que caracteriza el derecho $-y$ especialmente el derecho constitucional-actual). Así, el concepto de lo que es considerado "activo" es relativo y variable, pues demanda, siempre, una actividad interpretativa que no posee estándares definidos, cambiando en el tiempo y en el espacio. ${ }^{26}$ Además, el "activismo" no posee contenido ideológico preciso, pudiendo ser ejercido tanto en términos conservadores como en un sentido más liberal (el origen de la expresión, en Estados Unidos, está, incluso, vinculado a una noción de actuación conservadora por parte de la Suprema Corte); también no se le puede identificar, necesariamente, con la característica de realización y de garantía de la Constitución y de los derechos fundamentales, pues se podría perfectamente encuadrar un acto o decisión contrario a la Constitución como "activista".

Corte, especialmente porque, dentre as inúmeras causas que justificam esse comportamento afirmativo do Poder Judiciário, de que resulta uma positiva criação jurisprudencial do Direito, incluise a necessidade de fazer prevalecer a primazia da Constituição da República, muitas vezes transgredida e desrespeitada por pura, simples e conveniente omissão dos poderes públicos. [...] Práticas de ativismo judicial [...] tornam-se uma necessidade institucional, quando os órgãos do Poder Público se omitem ou retardam, excessivamente, o cumprimento de obrigaçōes a que estão sujeitos por expressa determinação do próprio estatuto constitucional, ainda mais se se tiver presente que o Poder Judiciário, tratandose de comportamentos estatais ofensivos à Constituição, não pode se reduzir a uma posição de pura passividade". Mello, (2008).

${ }^{24}$ El constitucionalista alemán Winfried Brohm cuestiona y al mismo tiempo alerta para una posible formación de una "oligarquía en la democracia" (Oligarchie in der Demokratie), provocada por una ampliación de las competencias del Tribunal Constitucional a partir de la noción de vinculación objetiva de los derechos fundamentales. En la visión del autor, una Constitución que protege el orden democrático de la oligarquía es una dádiva y, por lo tanto, esa misma protección no debe transformarse, ella propia, en una oligarquía. Cf. Brohm, (2001), p. 2.

25 Tushnet, (2007), pp. 415-436.

${ }^{26}$ Häberle, (1998d), pp. 59-92. 
Para los fines de este trabajo, sin embargo, pese a los distintos significados de la expresión, se tomará como referencia para la clasificación de las características y de algunos de los aspectos a ella relacionados, la noción de activismo identificada con el concepto de neoconstitucionalismo ${ }^{27}$, contexto en el cual el término ha ganado gran notoriedad y actualidad.

Así, a pesar de las dificultades operacionales, algunas consideraciones acerca del activismo judicial se hacen necesarias para su mejor comprensión, pudiendo ser designado, de manera general (en el sentido propuesto, conforme a lo referido en el párrafo anterior), por los siguientes aspectos:

\begin{tabular}{|c|c|}
\hline Activismo judicial & $\begin{array}{l}\text { al contrario de lo que ocurre en la judicialización, que es una tendencia } \\
\text { con diversas causas, el activismo consiste en un determinado modo de } \\
\text { interpretación y de aplicación de la Constitución }\end{array}$ \\
\hline \multirow{3}{*}{ Características } & $\begin{array}{l}\text { intensificación/ampliación de la actuación de la jurisdicción consti- } \\
\text { tucional }\end{array}$ \\
\hline & $\begin{array}{l}\text { expansión de la actuación del Judicial a ámbitos hasta entonces jamás } \\
\text { vistos } \rightarrow \text { El Poder Judicial "llama" para si la responsabilidad de garantía } \\
\text { de la Constitución y de los derechos fundamentales y, en su nombre, } \\
\text { desempeña funciones y toma decisiones que no le serían propiamente } \\
\text { atribuidas (ej.: destinación de recursos públicos; determinación de } \\
\text { actuación del legislador o satisfacción de omisiones legislativas, entre } \\
\text { otros) }\end{array}$ \\
\hline & relativización de la relación entre los Poderes \\
\hline \multirow[b]{2}{*}{ Causas } & $\begin{array}{l}\text { normatividad de la Constitución } \rightarrow \text { el reconocimiento de una "fuerza } \\
\text { normativa de la Constitución" abre camino para una actuación diferen- } \\
\text { ciada y activa del Poder Judicial y, particularmente, de los Tribunales } \\
\text { Constitucionales en el sentido de su realización }\end{array}$ \\
\hline & $\begin{array}{l}\text { inercia u omisión de los Poderes Públicos } \rightarrow \text { muchas veces, el Poder } \\
\text { Judicial es llamado a decidir acerca de cuestiones que serían de compe- } \\
\text { tencia del Poder Legislativo (ej.: reglamentación de determinada materia) } \\
\text { o del Poder Ejecutivo (ej.: creación/implementación de determinada } \\
\text { política pública), que, sin embargo, no son ejercidas }\end{array}$ \\
\hline
\end{tabular}

27 Acerca del neoconstitucionalismo, ver los diferentes abordajes y sus variantes en CARBOnELL, (2003). 


\begin{tabular}{|c|c|}
\hline & $\begin{array}{l}\text { abertura interpretativa } \rightarrow \text { proporciona una postura expansiva y activa } \\
\text { de los magistrados, que de ella se utilizan para, muchas veces, expandir } \\
\text { o restringir el texto normativo para más allá de su texto (ej.: sentencias } \\
\text { manipulativas) }\end{array}$ \\
\hline \multirow{3}{*}{$\begin{array}{l}\text { Formas de } \\
\text { actuación }\end{array}$} & $\begin{array}{l}\text { aplicación directa de la Constitución, independientemente de la } \\
\text { reglamentación por el legislador ordinario (ej.: eficacia directa de los } \\
\text { derechos fundamentales en las relaciones privadas) }\end{array}$ \\
\hline & $\begin{array}{l}\text { manifestación de inconstitucionalidad en casos no expresamente contra- } \\
\text { rios a la Constitución (ej.: verticalización partidaria de las coligaciones } \\
\text { de partidos políticos para todos los ámbitos federativos en determinada } \\
\text { elección-el Supremo Tribunal Federal aplicó el principio sin observar } \\
\text { la exigencia constitucional del principio de la anualidad) }\end{array}$ \\
\hline & $\begin{array}{l}\text { imposición de conductas y abstenciones al Poder Público } \rightarrow \text { "in- } \\
\text { tervención" en las actividades administrativas (ej.: distribución de } \\
\text { medicamentos, exigencia de prestación de transporte escolar por los } \\
\text { Municipios) }\end{array}$ \\
\hline
\end{tabular}

Delante de los diversos aspectos analizados, es posible decir, por lo tanto, que judicialización y activismo judicial constituyen fenómenos que se intercomunican, pero no se identifican. Ambos, no obstante, suscitan y conducen a cuestionamientos respecto a los límites y a la legitimidad de la jurisdicción constitucional.

Intentando responder estos cuestionamientos, hay diferentes y variadas teorías, que oscilan entre la defensa y la crítica a la actuación jurisdiccional. También estas teorías son, con todo, en cierta medida, insuficientes y parciales, pues tienen fundamentos bastante distintos, aspecto que, una vez más, dificulta el establecimiento de líneas claras de reflexión, generando una indeterminación acerca de sus conceptos centrales, lo que impide, muchas veces, que el debate sea hecho sobre bases adecuadas. Estos son algunos de los aspectos que serán, desde una perspectiva teórica, enfrentados en el tópico que sigue.

\section{JUDICIALIZACIÓN Y ACTIVISMO JUDICIAL EN PERSPECTIVA TEÓRICA: LAS DIFERENTES CONCEPCIONES ACERCA DEL ROL DE LA JURISDICCIÓN CONSTITUCIONAL EN EL ORDEN DEMOCRÁTICO}

Las cuestiones que envuelven los límites y la legitimidad de la jurisdicción constitucional son generalmente trabajadas, en términos teóricos, por la doctrina 
constitucional, a partir de una dicotomía que se establece entre dos corrientes opuestas, tradicionalmente conocidas como sustancialismo y procedimentalismo, conforme juegan, un rol más o menos activo y/o substancial a las cortes constitucionales, respectivamente.

Ocurre que esta discusión teórica, la mayoría de las veces, no es hecha en términos adecuados, pues: a) no hay homogeneidad en esta clasificación, una vez que las diferentes teorías poseen fundamentos bastante diversos; b) la clasificación de una postura como siendo más o menos activa se presenta bastante difícil, ya que el "activismo" se constituye en un concepto vacío de significado ${ }^{28}$, no siendo posible el establecimiento de estándares o criterios claros y objetivos que permitan calificar una determinada decisión judicial como "activista"; además, también el concepto de "activo" es relativo, siendo dependiente y variable conforme el punto de referencia adoptado, como se ha demostrado en el tópico anterior.

Tal aspecto, a su vez, apenas contribuye y refuerza las falacias acerca del tema, dificultando su discusión y conduciendo a los problemas de comprensión ya mencionados.

En este sentido, cuando se habla de determinadas teorías o corrientes de pensamiento, hay, generalmente, la idea de que existe una directriz común bien definida, que se traduce en una relativa uniformidad de argumentos y de elementos comunes.

$\mathrm{Al}$ analizarse los posicionamientos de diferentes autores ${ }^{29}$ sobre la materia, es posible no obstante percibir que, en verdad, lo que existe es una vasta pluralidad de concepciones y de argumentos con relación a los límites de actuación y a la legitimidad de la jurisdicción constitucional; razón por la cual acreditamos que substancialismo y procedimentalismo no pueden ser tomados como teorías o corrientes dotados de sentido unívoco. Abajo, intentamos analizar algunos de los aspectos que fundamentan esta posición.

a) Análisis de orden interno $x$ análisis de orden externo: el primer aspecto distintivo que se puede apuntar con relación a lo que fue dicho arriba dice relación, de una cierta manera, al locus de la exposición, pues es posible percibir

${ }^{28}$ Este aspecto ya fue analizado en el tópico anterior y puede ser profundizado en TusHNET, (2007), pp. 415-436.

${ }^{29}$ Para una lectura más profunda acerca del pensamiento de los autores citados en el presente artículo acerca de la jurisdicción constitucional, ver LEAL, (2007). 
que unos autores $^{30}$ (como Dworkin ${ }^{31}$-al discutir la vinculación moral o no de las decisiones judiciales, de donde resulta la defensa de una interpretación amplia de parte del magistrado- y Böckenförde ${ }^{32}$-al analizar las posibilidades de operacionalización de los derechos fundamentales- por ejemplo) trazan su análisis a partir de una perspectiva eminentemente metodológica, de cuño más interpretativo, hermenéutico (lo que, aquí, denominamos de análisis de orden interno), o sea, la discusión sobre el tema de la jurisdicción constitucional es hecha a partir de la actuación del juez y del Tribunal y sólo entonces ella adquiere, por vía refleja, repercusión para las demás esferas que están en su entorno, incluida, ahí, la relación con los demás poderes).

Otros lo hacen desde una perspectiva inversa, estableciendo los límites jurisdiccionales como punto de partida, como John Hart Ely ${ }^{33}$, que, a partir de la idea de representation reinforcing, sostiene la concentración de las actividades de naturaleza material y valorativa en la órbita representativa. Él parece, por lo tanto, trabajar la cuestión de la legitimidad y de las funciones de la jurisdicción constitucional desde una perspectiva de orden externo, es decir, el principal foco de su reflexión no reside en la actuación de los Tribunales propiamente dicha, sino que en su relación con los demás Poderes, o sea, sus límites resultan, implícitamente, del sistema de poder considerado en su totalidad. De ahí se puede afirmar que el tema es tratado, en estos casos, bajo una perspectiva más política que metodológica.

Así, en el primer caso, los límites de la jurisdicción son discutidos "desde dentro", a partir de una perspectiva interna, vinculada más a la interpretación; al paso que, en el segundo, estos límites son fijados "desde fuera", teniendo esta demarcación un carácter apenas derivado con relación a la discusión principal,

\footnotetext{
${ }^{30}$ Considerándose la propia complejidad del pensamiento de los autores estudiados, no es nuestro intento primero, aquí, encuadrarlos, de forma rígida, en una perspectiva o en otra, razón por la cual la referencia a ellos para sostener nuestras afirmaciones será hecha solamente con ocasión de los momentos que consideramos adecuados e imprescindibles, pues lo que pretendemos, aquí, no es trazar un cuadro comparativo entre ellos, sino que, a partir de ellos, construir algunas tesis que entendemos necesarias para la reflexión acerca de la jurisdicción constitucional. Delante de tal cuadro, el pensamiento de los diferentes constitucionalistas abordados no conforma el real y central objeto del presente tópico, sirviendo, tan sólo, como su "telón de fondo". Así, tienden nuestras apreciaciones a ser genéricas, más que propiamente analíticas.

${ }^{31}$ Dworkin, (1996), (1986), (2000), (2003).

32 BöCKENFÖRDE, (1999), (1976), (1991).

${ }^{33}$ ELY, (1980).
} 
que reside en la estructuración y en el funcionamiento del proceso político en una perspectiva "macro".

b) Variantes en el ámbito hermenéutico e interpretativo: las variantes en lo que dice relación con el ámbito hermenéutico e interpretativo pueden ser pensadas en dos niveles distintos. De un lado, la discusión pasa por la propia concepción del Derecho, es decir, ella demanda, en un cierto sentido, una reconsideración de las discusiones entre positivismo y derecho natural y, también, una discusión acerca de las fuentes del Derecho como un todo y del Derecho Constitucional en particular.

De otro lado, otro foco de reflexión puede ser percibido en el debate que se traba entre interpretativistas (interpretivism) y no interpretativistas (non interpretivism) $)^{34}$, pautado por la definición de lo que es la propia Constitución en cuanto documento político y jurídico, pues, para los primeros, su interpretación posee un carácter de rescate histórico que se traduce en la búsqueda y en la vinculación de los magistrados a los contenidos originalmente pretendidos por los fundadores (founding fathers), al paso que, para los segundos, este contenido debe ser actualizado más allá del mero texto legal, lo que implica y permite, a su vez, una interpretación de carácter más amplio y creativo.

Se podría decir, por lo tanto, que la primera concepción toma por fundamento la comprensión de la Constitución como manifestación del Poder Constituyente soberano, en cuanto que la segunda se afilia a la comprensión de la Constitución como un documento autónomo, vivo, en directa conexión con la evolución de la propia sociedad. Así, se tiene, en una, una primacía de la soberanía popular y, en la otra, una soberanía de la Constitución; en aquella hay una valoración del Legislativo, a quien cabe la determinación y la especificación de los contenidos constitucionales, mientras que en esta última hay una valoración del Poder Judicial como instancia privilegiada para esta actuación evolutiva.

De igual manera, el estándar o referencial hermenéutico adoptado por cada autor repercute directamente en la concepción de los límites de actuación y en la legitimidad de la jurisdicción constitucional, pues aquellos que se afilian a una teoría interpretativa de naturaleza más creativa, de construcción y de atribución de sentido al texto normativo, aproximándose, así, de la llamada "Nueva Hermenéutica" ${ }^{35}$, tienden a reconocer un mayor espacio de actuación a

${ }^{34}$ Para tanto, ver Berger, (1977).

35 Ver la nota de rodapé n. 20, supra. 
los tribunales, al paso que los adeptos de una teoría interpretativa más restrictiva, de cuño más positivista, basada en los métodos clásicos, tienden a limitar esta actuación, calificando, mucho más fácilmente que los primeros, una decisión como "activista".

c) Los diferentes "procedimentalismos": El elemento de unidad del así nombrado procedimentalismo está determinado por el aspecto de restricción interpretativa y de una postura de limitación del Poder Judicial en lo que concierne a la protección y a la realización de los contenidos constitucionales fundamentales, asociada a la idea de transferir a otros órganos la especificación de los contenidos valorativos de la Constitución.

Realizaremos algunas distinciones para una adecuada comprensión de la materia.

En este sentido, es posible distinguir entre dos tipos de "retirada" de competencia del Judicial y de transferencia al proceso político de las decisiones que envuelven contenidos de cuño valorativo. Mientras algunos sostienen esta limitación por medio de un refuerzo del sistema representativo, institucional, como John Hart Ely ${ }^{36}$, otros, como Häberle ${ }^{37}$ y Habermas ${ }^{38}$, lo hacen en virtud de una concepción que propone un proceso más amplio y abierto de participación política, que intenta avanzar con relación a la perspectiva tradicional a partir de una comprensión integrativa, activa y directa de los ciudadanos, especialmente en lo que dice respecto a las decisiones fundamentales de la sociedad o a aquello que Lawrence $\mathrm{H}$. Tribe ${ }^{39}$ denomina "elecciones constitucionales" (constitutional choices).

Aún así, es posible aseverar que mismo los procesos amplios de participación política propuestos presentan variaciones sustanciales, pues en Häberle, por ejemplo, ellos se refieren y están asociados a la propia interpretación de la Constitución en sentido amplio ("sociedad abierta de intérpretes de la Constitución" ${ }^{40}$ ), al paso que, para Habermas, por medio del obrar comunicativo, ellos poseen un carácter más amplio, direccionado a la política en general, incluida ahí la

\footnotetext{
36 ELY, (1980).

37 Häberle, (1982), (1998d), (1998c), (1998e), (1998a).

38 HABERMAS, (1998).

39 Tribe, (1985), Tribe; Dorf, (1991), Tribe, (1987).

${ }^{40}$ Häberle, (1998b), pp. 155-181.
} 
Constitución, o sea, la propuesta habermasiana tiene un objeto más general ${ }^{41}$, donde el foco central no reside, propiamente, en las figuras de la Constitución o de la jurisdicción constitucional; ellas son teorizadas, más, por vía refleja, en cuanto órganos e instituciones integrantes de la sociedad y de la organización política como un todo.

De ahí se puede afirmar que la distinción entre ambos reside en el hecho de que, en un caso, el aspecto del debate público parte de la Constitución -ella es, antes que nada, el objeto del debate-; ya en el segundo, el debate público es dirigido a la Constitución, pues ella sirve de fundamento al propio debate.

A pesar de que las concepciones procedimentales se basen en una noción de "retirada" de decisiones estratégicas del Judicial en beneficio de la sociedad y del proceso político, que debe tener una participación amplia y efectiva en las cuestiones que envuelven decisiones acerca de temas relevantes, se hace necesario considerar, con todo, que ellas no rompen, de forma definitiva, con el "activismo judicial", una vez que también ellas acaban por atribuir, en cierta medida, un papel activo a la jurisdicción constitucional en el control de los procedimientos de deliberación democrática, o sea: ellas tienden a reducir el activismo en términos materiales, defendiendo una "transferencia" de las decisiones de carácter valorativo a la sociedad, pero no lo hacen en la perspectiva procedimental, ya que resguardan una actuación activa a la jurisdicción en lo que concierne a la fiscalización, garantía y promoción del derecho de participación de los ciudadanos en el debate público.

d) Los diferentes sustancialismos: siguiendo en la línea de lo que se ha verificado en el punto precedente, también aquí es posible decir que las distinciones que se presentan en términos sustancialistas son intensas. En algunos casos, el fundamento para tal posición reside en una comprensión moral y valorativa de la Constitución, lo que conduce, a su vez, a lo que fue dicho en el ítem "b" de arriba, donde la cuestión de las fuentes del Derecho y, consecuentemente, de la interpretación, gana destaque. Esto se percibe, sobre todo, en el pensamiento de Dworkin, cuando intenta justificar la existencia de un derecho más amplio que el positivamente registrado en el texto constitucional, propugnando una "lectura moral de la Constitución". ${ }^{42}$

${ }^{41}$ Esta perspectiva más general del pensamiento de Habermas se justifica, a su vez, en virtud de su condición de filósofo, y no de jurista.

${ }^{42}$ La expresión es utilizada por el propio autor en la introducción de uno de sus libros, denominada The moral reading and the majoritarian premise. Cf. DwORKIN, (1996), p. 2. 
Otro punto distintivo en términos sustancialistas puede ser encontrado en la doctrina y en la jurisprudencia germánicas ${ }^{43}$, donde, por medio de construcciones acerca de la eficacia de los derechos fundamentales, acaban por ser reconocidas funciones de naturaleza creativa al Tribunal Constitucional, que se operan por medio de ponderaciones y juzgamientos de valor (jurisprudencia de valores), cuyos contornos y límites quedan abiertos, pues su real contenido solamente puede ser especificado en el fallo concreto. En este contexto, queda reservado a la jurisdicción constitucional un papel central y destacado en la concretización de los mismos.

Ante lo expuesto, es posible concluir, por consiguiente, que los términos "sustancialismo" y "procedimentalismo" son, en la mayoría de las veces, empleados de manera inadecuada y reduccionista, designando, con la misma denominación, teorías que, en verdad, son muy distintas. No hay dudas de que hay elementos entre ellas, pero, al discutir el tema, las variantes necesitan ser consideradas. Hecha esta constatación, no se intenta, con eso, abolir o criticar la denominación o la designación de corrientes teóricas distintas; lo que se quiere dejar claro, aquí, es que estos conceptos deben ser empleados con cautela, observándose, siempre, las particularidades de cada una de las teorías, así como su complejidad.

\section{CONCLUSIONES}

No hay dudas de que la jurisdicción constitucional ha ganado un relieve jamás visto en el contexto del Estado Democrático de Derecho; su actuación se aleja, en algunos aspectos, de aquella imaginada por Kelsen por ocasión de la creación de la figura del Tribunal Constitucional, adquiriendo nuevos delineamientos.

Este protagonismo está vinculado y es resultado, a su vez, entre otros aspectos, de la supremacía de la Constitución y de la dimensión objetiva reco-

\footnotetext{
43 Es posible apuntar, de manera superficial, una profunda distinción de carácter epistemológico entre las teorías americana y germánica con relación a la legitimidad de la jurisdicción constitucional, pues la primera tiende a concentrar la discusión en los aspectos interpretativos en general, desconociendo, aparentemente, en un sentido más depurado, la discusión sobre la concreción de los derechos fundamentales que caracteriza la doctrina alemana. Así, al desconocer la discusión sobre la dimensión objetiva de los derechos fundamentales, ella permanece, consecuentemente, con una visión más subjetiva e individual acerca de los mismos. Así, es natural que los debates que dicen respecto a la legitimidad de la jurisdicción constitucional se desvíen para otros focos, como es el caso de la interpretación y de la relación entre los poderes en una perspectiva que aquí denominamos de "externa".
} 
nocida a los derechos fundamentales, tenidos como principios, dependientes de interpretación y de concretización. Además, la preocupación con la fuerza normativa de la Constitución hace que los órganos encargados de su custodia ganen importancia, ampliándose, así, los espacios de su actuación.

Es en este contexto que surgen las referencias al "activismo judicial", que no puede, sin embargo, ser confundido con el fenómeno de la judicialización, que se opera en el ámbito de la relación entre Derecho y Política, repercutiendo, a su vez, también en la relación entre los Poderes.

A pesar de ser interdependientes, ambos conceptos no se confunden; caracterizándose la judicialización, más bien como el resultado de un proceso que posee múltiples factores y que conduce a una ampliación de los espacios de actuación de la jurisdicción constitucional en términos institucionales (resultantes, con todo, de elementos en cierta medida externos al Poder Judicial). En cambio, el activismo judicial tiene una dimensión y un carácter más interno, pudiendo ser clasificado, más bien, como algo vinculado a la postura del juzgador o del Tribunal en el cumplimiento de sus competencias. No se puede dejar de considerar, sin embargo, que, a pesar de tal distinción, ambos se relacionan, pues el proceso de judicialización, en virtud de sus características, favorece el surgimiento de conductas "activistas" (aunque, conforme a lo aducido en el texto, los parámetros de lo que sea una decisión o sentencia activista no pueden ser fijados según criterios objetivos, dejando margen a interpretaciones). Por otro lado, el activismo puede hacerse presente incluso en un contexto de competencias reducidas o de restricción a la actuación de la jurisdicción constitucional; así, una decisión que en un determinado tiempo y lugar podría ser tenida como activista puede ser recibida como absolutamente "normal" en otro, pues los conceptos son -como ya dijimos- relativos.

Ambos, no obstante, son frecuentemente tomados como sinónimos, aspecto que en nada contribuye para una discusión adecuada de la materia. En la misma línea, también las teorías que se proponen estudiar el tema de la legitimidad de la jurisdicción constitucional a partir de la dicotomía sustancialismo y procedimentalismo, los que poseen fundamentos bastante diversos, no prestándose, pues, a generalizaciones reduccionistas, una vez que los conceptos suscitados son, en la mayoría de los casos, conceptos vagos e imprecisos, que acaban, frecuentemente, siendo invocados de manera "liviana" y con fuerte carácter retórico.

Tales aspectos necesitan, por lo tanto, ser debidamente considerados si se quiere proceder a una reflexión acerca de tema tan fluido y complejo como el 
de los límites y de la legitimidad democrática de la jurisdicción constitucional, que no puede darse en términos generalistas y reduccionistas.

En este sentido, tampoco se pueden indicar patrones fijos para la actuación de la jurisdicción constitucional, de manera que sus contornos son tan imprecisos y variables cuanto los conceptos aquí analizados. Así, esta es una pregunta cuya respuesta permanece siempre abierta, lo que no impide que esa respuesta sea permanentemente buscada o, al menos, discutida. Es desde tal punto de vista que el presente artículo ha intentado trabajar, críticamente, algunos de los conceptos tenidos como fundamentales para esta discusión, visando contribuir no tanto para la respuesta, como para su búsqueda.

\section{Bibliografía}

Abellán, Marina Gascón (2003). "Los límites de la jurisdicción constitucional", en: LAPORTA, Francisco (org.). Constitución: problemas filosóficos (Madrid: Centro de Estudios Políticos y Constitucionales).

BARroso, Luis Roberto (2009). "Judicialização, ativismo e legitimidade democrática”. In: Revista Eletrônica de Direito do Estado, n. 18, abr./jun. (Fecha de consulta: 1 de diciembre de 2011). Disponible en: www.direitodoestado. com.br.

BERGER, Raoul (1977). Government by Judiciary: the transformation of the Fourteenth Amendment (Cambridge, Massachussetts: Harvard University Press).

BÖCKENFÖRDE, Ernst-Wolfgang (1976). "Die Methoden der Verfassungsinterpretation: Bestandsaufnahme und Kritik", en: Neue Juristische Wochenschrift (NJW) (Heft 46, 16. November).

, Ernst-Wolfgang (1991). Staat, Verfassung, Demokratie: Studien zur Verfassungstheorie und zum Verfassungsrecht (Frankfurt a.M.: Suhrkamp).

, Ernst-Wolfgang (1999). "Begriff und Probleme des Verfassungsstaates", In: Staat, Nation, Europa: Studien zur Staatslehre, Verfassungstheorie und Rechtsphilosophie (Frankfurt a. M.: Suhrkamp).

, Ernst-Wolfgang (1999). "Verfassungsgerichtsbarkeit: Strukturfragen, Organisation, Legitimation", en: Neue Juristische Wochenschrift (NJW) (Heft 1).

BroHm, Winfried (2001). "Die Funktion des BVerfG - Oligarchie in der Demokratie?”, en: Neue Juristische Wochenschrift (NJW) (Heft 01).

Carbonell, Miguel (2003). Neoconstitucionalismo(s) (Madrid: Trotta). 
Cittadino, Gisele Guimarães (2002). "Judicialização da política, constitucionalismo democrático e separação de poderes”, en: VIANNA, Luiz Werneck (Org.). A democracia e os três poderes no Brasil (Belo Horizonte: Editora UFMG; Rio de Janeiro: IUPERJ/FAPERJ).

Coelho, Sacha Calmon Navarro (1992). Controle da constitucionalidade das leis e do poder de tributar na Constituição de 1988 (Belo Horizonte: Del Rey).

Denninger, Erhard (1990). Der gebändigte Leviathan. (Baden-Baden: Nomos).

Dworkin, Ronald (1996). Freedom's law (Cambridge, Massachusetts: Harvard University Press).

, Ronald (2000). Sovereign virtue: the theory and practice of equality ( $2^{\text {nd }}$ print. Cambridge, Mass.: Harvard University Press).

, Ronald (2003). "The judge's new role: should personal convictions count?", en: Journal of International Criminal Justice (n. 1. Oxford University Press).

, Ronald (1986). Law's empire (Cambridge, Massachusetts: Harvard University Press).

ELIA, Leopoldo (1987). "Constitucionalismo cooperativo, racionalidad y sentencias aditivas en la jurisprudencia italiana sobre control de normas", en: PINA, António López. División de poderes e interpretación: hacia una teoría de la praxis constitucional, (Madrid: Tecnos).

Ely, John Hart (1980). Democracy and distrust: a theory of judicial review (Cambridge, Massachusetts: Harvard University Press).

EnTERRía, Eduardo García de (1985). La constitución como norma y el Tribunal Constitucional (Madrid: Civitas).

GADAMER, Hans-Georg (1972). Warheit und Methode: Grundzüge einer philosophischen Hermeneutik (Tübingen: Mohr).

Grimm, Dieter (2006). Constituição e política (Traducc. de Geraldo de Carvalho. Belo Horizonte: Del Rey).

HaAs, Evelyn (2004). "La posición de los magistrados de la Corte Constitucional Federal alemana y su significado para la vida jurídica y la sociedad", en: Anuario de Derecho Constitucional Latinoamericano (10 ed. Montevideo: Konrad Adenauer).

HäBERLE, Peter (1982). Verfassungslehre als Kulturwissenschaft (2. Auflage. Berlin: Duncker \& Humblot). 
, Peter (1998a). "Die Grundrechte im demokratischen Staat (1974) mit Nachtrag (1978)", en: Verfassung als öffentlicher Prozess: Materialen zu einer Verfassungstheorie der offenen Gesellschaft (3. Auflage. Berlin: Duncker \& Humblot).

, Peter (1998b). "Die offene Gesellschaft der Verfassungsinterpreten (1975) mit Nachtrag (1978)", en: Verfassung als öffentlicher Prozess: Materialen zu einer Verfassungstheorie der offenen Gesellschaft (3. Auflage. Berlin: Duncker \& Humblot).

, Peter (1998c). "Verfassungsinterpretation als öffentlicher Prozess - ein Pluralismus- konzept", en: Verfassung als öffentlicher Prozess: Materialen zu einer Verfassungstheorie der offenen Gesellschaft (3. Auflage. Berlin: Duncker $\&$ Humblot).

, Peter (1998d). "Zeit und Verfassung (1974) mit Nachtrag (1978)", en: Verfassung als öffentlicher Prozess: Materialen zu einer Verfassungstheorie der offenen Gesellschaft (3. Auflage. Berlin: Duncker \& Humblot).

, Peter (1998e). "Verfassungsprozessrecht als konkretisiertes Verfassungsrecht im Spiegel der Judikatur des BVerfG (1976) mit Nachtrag (1978)", en: Verfassung als öffentlicher Prozess: Materialen zu einer Verfassungstheorie der offenen Gesellschaft (3. Auflage. Berlin: Duncker \& Humblot);

Habermas, Jürgen (1990). Strukturwandel der Öffentlichkeit (Frankfurt a.M.: Suhrkamp).

, Jürgen (1995). Theorie des kommunikativen Handelns: Handlungsrationalität und gesellschaftliche Rationalisierung (Frankfurt a.M.: Suhrkamp).

, Jürgen (1998). Faktizität und Geltung: Beiträge zur Diskurstheorie des Rechts und des demokratischen Rechtsstaats (Frankfurt a.M: Suhrkamp).

HaLtern, Ulrich R (1998). Verfassungsgerichtsbarkeit, Demokratie und Misstrauen: das Bundesverfassungsgericht in einer Verfassungstheorie zwischen Populismus und Progressivismus (Berlin: Duncker \& Humblot).

Heidegger, Martin (1986). Sein und Zeit (16. Auflage. Tübingen: Niemeyer).

ISENSEE, Josef (1996). "Bundesverfassungsgericht - quo vadis?", en: Juristen Zeitung (JZ) (22. November).

Kelsen, Hans (1929a). Wesen und Entwicklung der Staatsgerichtsbarkeit. In: Veröventlichung der Vereinigung der deutschen Staatslehrer (VVDStRL) (Band 5. Berlin: Walter Gruyter).

, Hans (1929b). Wesen und Wert der Demokratie (Tübingen: Mohr). 
KocH, Hans-Joachim (1986). "Die Begründung von Grundrechtsinterpretationen", en: Europäische Grundrechte Zeitschrift (EuGRZ) (Heft 11/12, 30. Juni).

LeAL, Mônia Clarissa Hennig (2007). Jurisdição Constitucional aberta. Reflexões acerca dos limites e da legitimidade da Jurisdição Constitucional na ordem democrática - uma análise a partir da teoria constitucional alemã e norteamericana (Rio de Janeiro: Lúmen Júris).

, Mônia Clarissa Hennig Leal (2006). "Interpretação conforme à Constituição x nulidade parcial sem redução de texto: semelhanças, diferenças e reflexão sobre sua operacionalização pelo Supremo Tribunal Federal", en: REIS, J. R. dos; LEAL, R. G. Direitos sociais e politicas públicas: desafios contemporáneos (Santa Cruz do Sul: Edunisc, Tomo 6).

Maus, Ingeborg (2000). "O Judiciário como superego da sociedade - sobre o papel da atividade jurisprudencial na 'sociedade órfă'”. (Traducc. Martonio Mont'Alverne Barreto Lima e Paulo Menezes Albuquerque), en: Novos Estudos (n. 58. São Paulo: CEBRAP, novembro). pp. 183-202.

Mello, Celso de (2008). Discurso na posse do Ministro Gilmar Ferreira Mendes na presidência do Supremo Tribunal Federal brasileiro, em 23 de abril de 2008. (Fecha de consulta: 1 de diciembre de 2011). Disponible en: http:// www.stf.jus.br.

Mendes, Gilmar Ferreira (1998). Jurisdiçãa constitucional: o controle abstrato de normas no Brasil e na Alemanha ( $2^{a}$ ed. São Paulo: Saraiva).

RobBers, Gerhard (1990). "Die historische Entwicklung der Verfassungsgerichtsbarkeit", en: "Juristische Schulung: Zeitschrift für Studium und Ausbildung (JuS)” (Heft 4. München: C.H. Beck).

SÁncheZ, José Acosta (1998). "Transformaciones de la Constitución en el siglo XX”, en: Revista de Estudios Políticos (n. 100, abril-junio).

SCHLINK, Bernhard (1989). "Die Entthronung der Staatsrechtswissenschaft durch die Verfassungsgerichtsbarkeit”, en: Der Staat. Zeitschrift für Staatslehre, öffentliches Recht und Verfassungsgeschichte (Band 28. Berlin: Duncker \& Humblot).

Schwabe, Jürgen (1971). Die sogenannte Drittwirkung der Grundrechte. Zur Einwirkung der Grundrechte auf den Privatsrechtverkehr (München: Goldmann).

SILVA, Paulo Napoleão Nogueira da (1992). A evolução do controle da constitucionalidade e a competência do Senado Federal (São Paulo: Revista dos Tribunais). 
STReCK, Lênio Luiz (2001). "Os meios e acesso do cidadão à jurisdição constitucional, a Argüição de Preceito Fundamental e a crise de efetividade da Constituição brasileira”, en: Souza Cruz, Álvaro Ricardo de (org.). Hermenêutica e jurisdição constitucional, (Belo Horizonte: Del Rey).

Tavares, André Ramos (2005). Teoria da justiça constitucional (São Paulo: Saraiva).

Tribe, Lawrence H (1985). Constitutional choices (Cambridge, Massachusetts: Harvard University Press).

, Lawrence H (1985). God save this honorable Court: how the choice of Supreme Court justices shapes our History (Harvard: Random House). , Lawrence H (1988). American Constitutional Law ( $2^{\text {nd }}$ edition. Cambridge: Foundation Press).

, Lawrence H.; DORF, Michael (1991). On reading the Constitution (Cambridge, Massachusetts: Harvard University Press); TRIBE, Lawrence H (1987). "Roots and limits of judicial review", en: Constitutional Roots, Rights and Responsabilities, (n. 23. Cambridge: Keens Company).

Tushnet, Mark (2007). "The United States of America”, en: Dickinson, Brice. Judicial activism in Common Law Supreme Courts (New York: Oxford University Press). 
